Universitas, Volumen 2, Número 2, 2008,39-45, ISSN 2071-2573

๑) 2008 UNAN-León, Editorial Universitaria

\title{
Seroprevalencia de VIH/SIDA en trabajadoras del sexo y conductores de transporte pesado de la cuidad de León
}

\author{
Eliette Patricia Gutiérrez R. ${ }^{1}$, Lissette del Pilar Rubí Ortíz ${ }^{1}$, Orlando Mayorga Pérez ${ }^{{ }^{\star}}$ \\ 1. Estudiantes de Bioanálisis Clínico. Universidad Nacional Autónoma de Nicaragua, León (UNAN-León). \\ 2. Profesor titular Departamento de Microbiología y Parasitología, Facultad de Ciencias Médica, Universidad Nacional \\ Autónoma de Nicaragua, León (UNAN-León).
}

\section{RESUMEN}

\begin{abstract}
EI VIH/SIDA es un problema creciente en Nicaragua, particularmente en el occidente del país. Un estudio descriptivo de corte transversal fue realizado para identificar la seroprevalencia de VIH/SIDA y las conductas de riesgo en trabajadoras sexuales y conductores de transporte pesados que circulan por el by pass de León. La muestra estuvo comprendida por 100 personas. Los participantes después de firmar un consentimiento informado por escrito se les llenó una ficha epidemiológica y se les tomó una muestra sanguínea para ser sometida a la prueba de VIH.

La seroprevalencia de VIH/SIDA fue $1 \%$ en conductores de transporte pesado, las conductas de riesgo más importantes fueron: no uso de preservativos, frecuencia de I.T.S. y número de compañeros sexuales. Las trabajadoras sexuales se realizan la prueba de VIH/SIDA más frecuentemente que los conductores de transporte pesado. Se concluye que de cada 50 conductores de transporte pesado que circulan por el área del by pass de León, al menos uno puede estar positivo al VIH y que las trabajadoras sexuales hacen mejor uso de la medidas preventivas para VIH/Sida.
\end{abstract}

Palabras Clave: VIH, Trabajadoras sexuales, transportistas, Nicaragua.

\section{INTRODUCCIÓN}

El VIH fue descubierto e identificado como el agente de la naciente epidemia de SIDA por el equipo de Luc Montagnier en Francia, 1983. En ese mismo año se demuestra que la enfermedad podía adquirirse tanto por coito anal como vaginal..$^{[1,2]}$

EI SIDA representa la expresión patológica final de la infección por VIH cuya capacidad para atacar los linfocitos CD4 supone la destrucción del sistema inmunitario del paciente afectado, dejándolo expuesto a la agresión de numerosas infecciones que conllevan a la muerte del enfermo[1]. El virus se transmite por contacto directo y para ello es necesaria la presencia de una cantidad suficiente de virus, como la encontrada en el semen y otros líquidos corporales tales como flujo vaginal, sangre y en menor cantidad, en la leche materna. Por lo tanto, el contagio del VIH se produce por vía sexual, sanguínea y de la madre al feto o al recién nacido. ${ }^{[3]}$

A finales del 2004, en el mundo el número de personas que conviven con el VIH/SIDA, se calculó en 40 millones, de las cuales 17.6 millones son mujeres, estadísticas recientes estiman que las mujeres pasaron a constituir la mitad de las personas que viven con VIH/SIDA, más aún las profesionales del sexo. ${ }^{[4,5]}$

En América Latina en el 2003 unas 84 mil personas fallecieron a causa del SIDA, mientras que otras 200 mil contrajeron la infección. Un estudio internacional que se hizo en el 2004 indicó que la prevalencia del $\mathrm{VIH}$ entre profesionales femeninas del sexo varía desde menos del $1 \%$ en Nicaragua, $2 \%$ en Panamá, $4 \%$ en el Salvador y más del $10 \%$ en Honduras. ${ }^{[6]}$

En Nicaragua el primer caso de VIH/SIDA, se oficializó en 1987, desde entonces el número de afectados se ha mantenido en un ascenso continuo y acelerado. Desde 1987 hasta diciembre del 2002 se acumuló un total de 997 casos de $\mathrm{VIH} / \mathrm{SIDA}$ en todo el país y la tasa de prevalencia era de $3.63 \times 100$ mil habitantes. La feminización que lleva la epidemia hasta el año 2005 en Nicaragua con una razón de masculinidad que ha pasado de $7: 1$ a 2:1 es alarmante para las mujeres..$^{[5]}$

León ocupa el cuarto lugar a nivel nacional en casos de VIH/SIDA reportados, ya que es el corredor entre el occidente y el sur del país mas utilizado por el transporte pesado internacional y tiene frontera con Chinandega uno de los departamentos con mayor incidencia de casos de VIH. ${ }^{[7,8]}$ Para finales del año 2006 el Ministerio de salud León tenía en total 154 casos VIH/SIDA y hasta mayo del 2007 se han registrado 24 casos nuevos. ${ }^{[9]}$

Por tanto estudiar la seroprevalencia y comportamientos de riesgo de $\mathrm{VIH}$ en conductores de transporte pesado y trabajadoras sexuales es importante ya que estos grupos no son objeto de una vigilancia sistemática por las autoridades de salud de nuestro país pese a que tienen un alto riesgo de contraer la infección. 


\section{DISEÑO METODOLÓGICO}

Un estudio descriptivo de corte transversal se realizó en 100 personas que se movilizaban en el área del by pass de la ciudad de León en el periodo de Mayo - Agosto del 2007. Este sector de la ciudad es regularmente visitado por trabajadoras sexuales y conductores de transporte pesado los cuales se constituyeron como grupos de estudio.

La ciudad de León se ubica a $90 \mathrm{~km}$ de Managua, tiene una población estimada en 190.000 habitantes, tradicionalmente es una ciudad universitaria.

Previa aprobación de este estudio por parte del comité de ética de la Facultad de Ciencias Médica de la UNANLeón y después firmar un consentimiento informado por escrito, 50 mujeres trabajadoras del sexo y 50 hombres conductores de transporte pesado fueron captados en el área de estudio antes mencionada, siendo los criterios de inclusión: ser mayor de edad, estar ubicados en el área del by pass, aceptar y firmar la carta de consentimiento informado para participar en este estudio.

Una vez obtenido el consentimiento de participación y después de explicarle los objetivos del estudio se procedió al llenado de de un formulario el cual contenía datos personales y de comportamiento de riesgo para adquirir el $\mathrm{VIH}$, la fuente de información fue primaria a través de una entrevista directa y confidencial a los y las participantes.

Posterior a la entrevista se procedió a la toma de una muestra de $5 \mathrm{cc}$ de sangre venosa de la vena antecubital en tubos al vacío y sin anticoagulante de acuerdo al protocolo convencional para la toma de este tipo de muestra. Las muestras fueron transportadas al laboratorio del Departamento de Microbiología y Parasitología de la Facultad de Ciencias Médicas, en un termo a una temperatura entre 4 y $8^{\circ} \mathrm{C}$ y luego fueron centrifugadas para obtener el suero. Los sueros se guardaron a temperatura de $-20^{\circ} \mathrm{C}$ hasta su procesamiento.

A cada muestra de suero se le realizó la prueba rápida Capillus y posteriormente a las muestras que resultaron positivas se les realizó el test inmunocromatográfico Uni-Gold.

Los resultados obtenidos fueron clasificados como reactivos y no reactivos de acuerdo a los criterios establecidos por el fabricante para cada tipo de prueba.
Las muestras de suero que resultaron reactivas con la última prueba, se enviaron al Centro Nacional de Diagnóstico y Referencia Concepción Palacios; MINSA central, para su respectiva confirmación con Western Blot.

Una vez obtenidos los datos de las variables, éstas fueron introducidos en una base de datos y posteriormente procesados mediante el programa Epi info versión 6.0. Se calcularon tasas, promedios, rangos y porcentajes, los cuales fueron expresados en valores absolutos y relativos, así como también en tablas y/o gráficos.

\section{RESULTADOS Y DISCUSIÓN}

\section{Datos generales de los participantes del estudio}

Durante el período comprendido de Mayo-Agosto del 2007, se recolectaron un total de 100 muestras sanguíneas, 50 de las cuales pertenecían a mujeres trabajadoras del sexo de esta ciudad y 50 a conductores de transporte pesado que circulan en el by pass de la ciudad de León.

En cuanto a la edad, el grupo etáreo predominante entre varones y mujeres fue el de mayores de 30 años, reflejado en la tabla 1, con un $42 \%$ en ambos sexos, dato que para el caso de las trabajadoras sexuales no concuerda con estudios similares a nivel nacional e internacional que reflejan un predominio de grupos etáreos menores de 30 años. ${ }^{[10]}$ Esto probablemente se deba a que las trabajadoras sexuales de menor edad les sea más rentable permanecer en otros lugares dedicados a este tipo de servicio donde la afluencia de clientes es mayor.

El grupo etáreo predominante entre los conductores de transporte pesado, se relaciona principalmente con su ocupación, ya que generalmente este tipo de trabajo por reglamento de transporte en diferentes países, le es encomendado a personas de edades superiores a 25 años.

Tabla 1. Distribución de la población de estudio según grupo etáreo

\begin{tabular}{ccc}
\hline Variables & $\begin{array}{c}\text { Conductores de T. } \\
\text { Pesado }\end{array}$ & $\begin{array}{c}\text { Trabajadoras } \\
\text { sexuales }\end{array}$ \\
\hline Edad & Masculino $n=50$ & Femenino $n=50$ \\
$18-21$ & $18 \%$ & $30 \%$ \\
$22-25$ & $24 \%$ & $16 \%$ \\
$26-29$ & $16 \%$ & $12 \%$ \\
$\geq 30$ & $42 \%$ & $42 \%$ \\
Total & $100 \%$ & $100 \%$ \\
\hline
\end{tabular}


Respecto a la ocupación del total de las Trabajadoras Sexuales el $74 \%$ se dedicaban exclusivamente a este trabajo y en menor proporción a otros tales como: doméstica $(6 \%)$, amas de casa (14\%) u otros $(6 \%)$. Estos hallazgos concuerdan con estudios realizados en trabajadoras sexuales(ver figura 1). Esta situación indica que la ocupación alternativa de estas trabajadoras no les brinda los ingresos suficientes para cubrir sus necesidades básicas, o que por otros motivos tales como violencia intrafamiliar y abuso sexual tengan que dedicarse al trabajo sexual. ${ }^{[11]}$

Figura 1. Ocupción de las trabajadoras sexuales

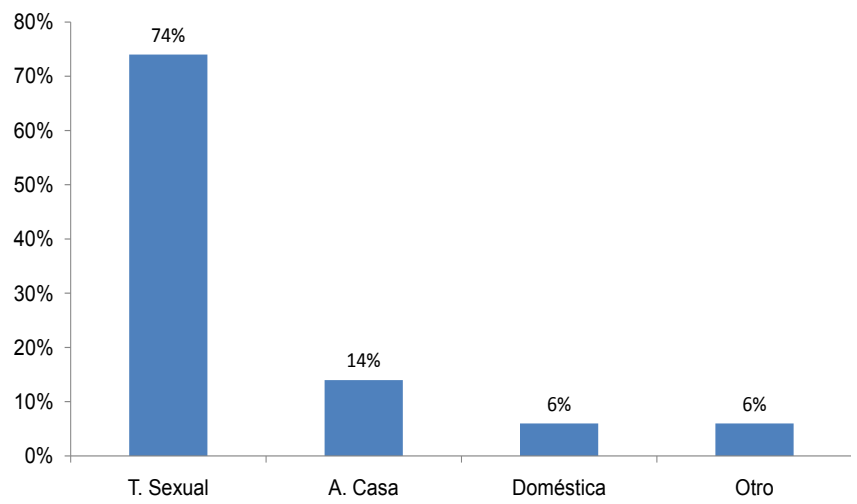

Al consultársele tanto a conductores como a trabajadoras del sexo si alguna vez se habían realizado la prueba de $\mathrm{VIH}$, el $66 \%$ de las mujeres y $36 \%$ de los hombres respondieron que al menos una vez en su vida se la habían hecho.(ver figura 2)

Es importante señalar que las trabajadoras del sexo le dan mayor importancia al hecho de realizarse la prueba del VIH que los transportistas, lo que nos indica que los hombres aunque pertenecen a un grupo de riesgo importante, probablemente debido a su pensamiento machista creen estar menos expuestos a esta enfermedad y por esta razón la mayoría de ellos aseguraron nunca haberse realizado la prueba ya sea por miedo a descubrir que eran seropositivos o porque creían que tomaban las precauciones necesarias como para sentir seguridad absoluta de no estar infectados con el virus.

Este tipo de comportamiento se considera de cuidado ya que pertenecen a un grupo de alto riesgo para contraer el VIH tanto por su ocupación como por su comportamiento sexual.

Comportamientos de riesgo para $\mathrm{VIH}$ en trabajadoras sexuales y conductores de transporte pesado. En la figura 3 se observa que la escolaridad predominante alcanzada por los encuestados es la educación secundaria con un $48 \%$ en los hombres, seguida por la educación primaria
Figura 2. Porcentaje de participantes que se han realizado la prueba de VIH alguna vezs trabajadoras sexuales

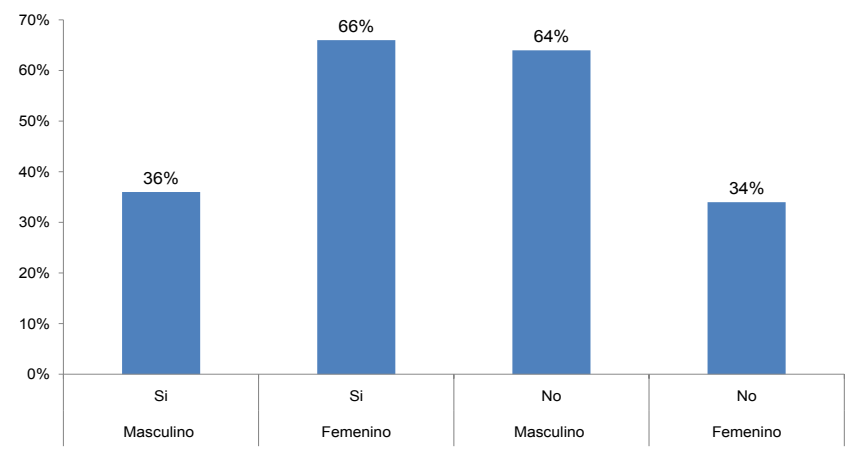

Figura 3. Escolaridad alcanzada

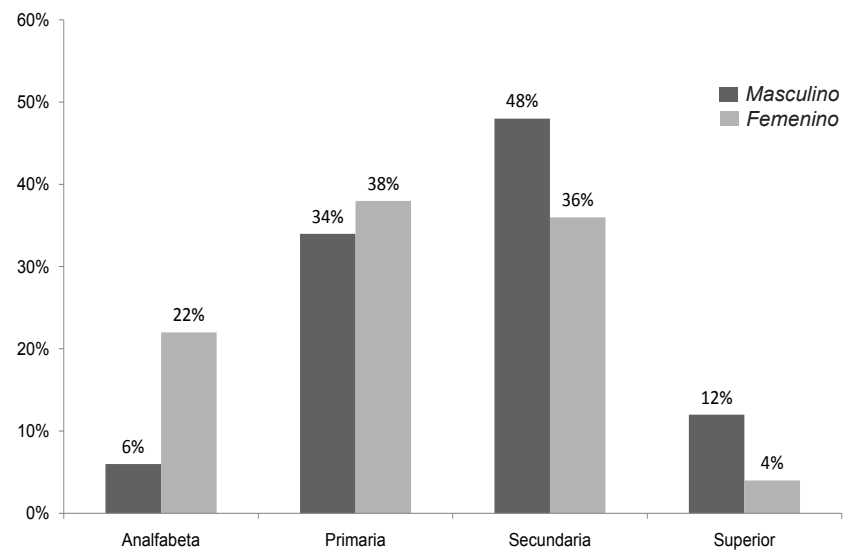

con $38 \%$ en las mujeres, indicándonos ser un grupo que podría tener un conocimiento de la situación actual del VIH que incida en su comportamiento sexual. ${ }^{[10,11]}$ Sin embargo, es necesario señalar que el $22 \%$ de las mujeres en estudio nunca han ingresado a una escuela lo cual nos sugiere que podrían tener comportamientos de riesgo para adquirir la infección con $\mathrm{VIH}$.

En cambio, la baja escolaridad encontrada entre los varones $(6 \%)$ nos indica que el riesgo de desarrollar comportamiento de riesgo en este grupo es relativamente menor comparado con el de las mujeres. El nivel de educación superior es tres veces mayor en hombres que en mujeres.

El número de compañeros sexuales que tienen las trabajadoras del sexo por día, es variable, la mayoría $(48 \%)$ tienen de 1 a 3 clientes, seguido por un $36 \%$ que tienen contacto con 4 - 6 hombres y en menor proporción (6\%) tienen 10 o más compañeros sexuales en un día.

Estos resultados reflejan un comportamiento similar a estudios realizados en Corinto y Chinandega en este mismo grupo poblacional en donde las Trabajadoras Sexuales ya sea por la situación económica o por 
insistencias de sus clientes se ve forzadas a tener relaciones sin protección y así aumenta la probabilidad de contraer el virus y más aún a medida que aumenta el número de compañeros sexuales o clientes. ${ }^{[12,13]}$ (ver figura 4)

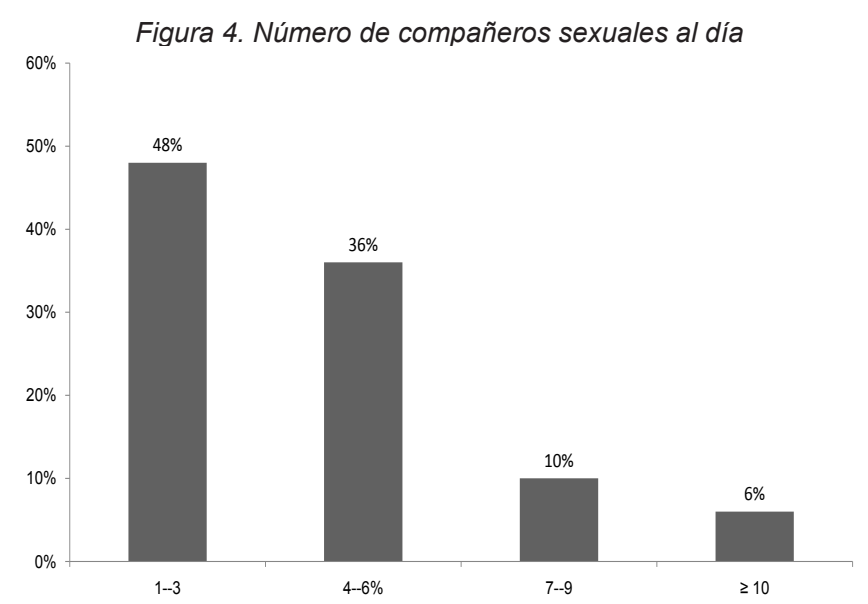

La afinidad que tienen los encuestados por el sexo opuesto o el mismo sexo se resume en la figura 5, observando que el $80 \%$ de los hombres y el $90 \%$ de las mujeres tienen afinidad por el sexo opuesto.

La minoría de los encuestados no tiene inconveniente con relación al sexo correspondiendo esto al $6 \%$ para los varones y el $8 \%$ para las mujeres. Estos hallazgos vienen a reafirmar lo que revelan la mayoría de los estudios sobre $\mathrm{VIH}$ en grupos de riesgo, los cuales revelan que los heterosexuales son en la actualidad los más afectados en cuanto a la infección por VIH en relación a los homosexuales. ${ }^{[12,14]}$

Podemos observar en la tabla 2 que el $78 \%$ de las mujeres y el $42 \%$ de los varones refirieron utilizar siempre preservativo, el $16 \%$ de las mujeres y el $44 \%$ de los varones dijeron utilizarlo ocasionalmente, mientras que un mínimo de las trabajadoras sexuales (6\%) nunca han usado preservativo, comparado al $14 \%$ de los conductores que no tienen protección a la hora del sexo.

De los encuestados un 22\% (mujeres) presenta dificultad para la obtención de preservativo y un $4 \%$ (hombres) igualmente no los pueden conseguir; sin embargo la mayor parte de las personas en cuestión aseguraron que de una u otra forma los obtenían, correspondiendo esto al $78 \%$ para las trabajadoras del sexo y un $96 \%$ para los conductores.

Respecto al uso de condones como medio de protección es importante señalar que las trabajadoras sexuales

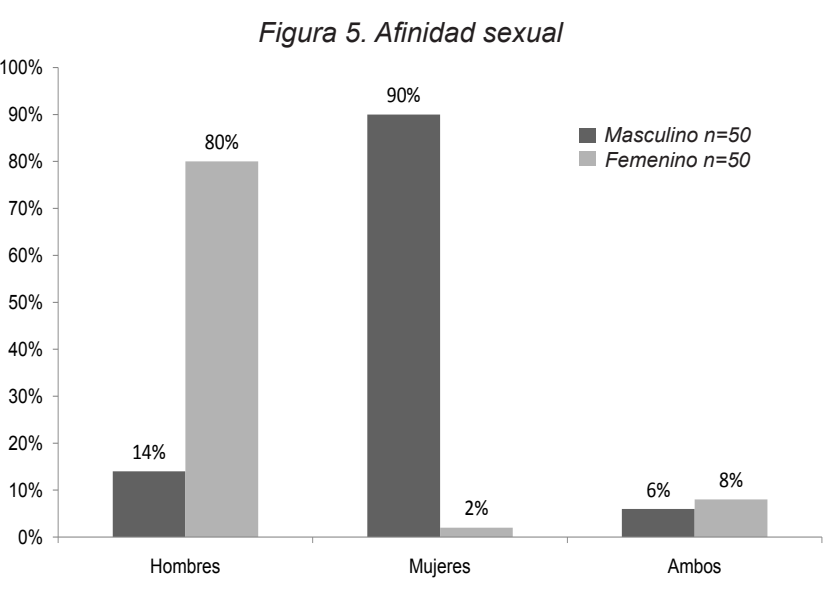

Tabla 2. Uso de preservativos y dificultad para la obtención

\begin{tabular}{cccccc}
\hline \multirow{2}{*}{ Variables } & \multicolumn{3}{c}{ Uso de preservativos } & \multicolumn{3}{c}{$\begin{array}{c}\text { Dificultad para } \\
\text { la obtención }\end{array}$} \\
\cline { 2 - 6 } & Siempre & Ocasionalmente & Nunca & Si & No \\
\hline $\begin{array}{c}\text { Trabajadoras del } \\
\text { sexo } \\
\text { Conductores }\end{array}$ & $78 \%$ & $16 \%$ & $6 \%$ & $22 \%$ & $78 \%$ \\
\hline
\end{tabular}

se protegen más que los conductores de transporte pesado, lo cual implica que el riesgo aumenta o es mayor para las parejas de éstos conductores, que al regresar a sus hogares ponen en riesgo la salud de sus cónyuges al contraer el VIH u otras infecciones de transmisión sexual.

Estos hallazgos coinciden con un reporte del Ministerio de Salud de Nicaragua y algunos países América del Sur en donde se demuestra que los hombres en su mayoría no usan preservativos por un sin numero de razones entre estas que el preservativo les reduce la sensibilidad en el momento del acto sexual. ${ }^{[12]}$

En cuanto a que si los participantes habían tenido relaciones fuera de su ciudad, se encontró que existe igual proporción en cuanto a Sí o No en el caso de las trabajadoras del sexo para un $50 \%$. En cambio para los conductores debido a su ocupación laboral, el Sí fue representativo correspondiendo al $70 \%$, ver tabla 3 , llama la atención como este factor representa un riesgo de transmisión del VIH.

En la figura 6 se observa la frecuencia de infecciones de transmisión sexual tanto en las trabajadoras del sexo como en los conductores, indicándonos que el $30 \%$ de los conductores y el $26 \%$ de las mujeres refieren haber tenido algún tipo de infección de transmisión sexual. 
Tabla 3. Relaciones sexuales fuera de la ciudad

\begin{tabular}{ccc}
\hline \multirow{2}{*}{ Variables } & Masculino & Femenino \\
\cline { 2 - 3 } & $\mathrm{n}=50$ & $\mathrm{n}=50$ \\
\hline $\mathrm{Si}$ & $70 \%$ & $50 \%$ \\
$\mathrm{No}$ & $30 \%$ & $50 \%$ \\
\hline
\end{tabular}

Un factor de riesgo importante para contraer el VIH tanto en hombres como en mujeres es la frecuencia de I.T.S., la cual varía de acuerdo comportamientos de riesgo como el no uso de medios de protección. Este estudio revela una mayor frecuencia de I.T.S. entre los conductores en relación a las trabajadoras sexuales, ya que los primeros no toman las debidas precauciones porque nunca usan el condón o lo usan de vez en cuando, esta situación se da por tabúes que la misma sociedad crea.

Se puede observar en el siguiente gráfico que la infección por $N$. gonorrhoeae fue la que predominó en ambos sexos seguida por T. Pallidum, siendo mayor para el grupo de los conductores de transporte pesado.

Figura 6. Frecuencia de ITS en los pacientes

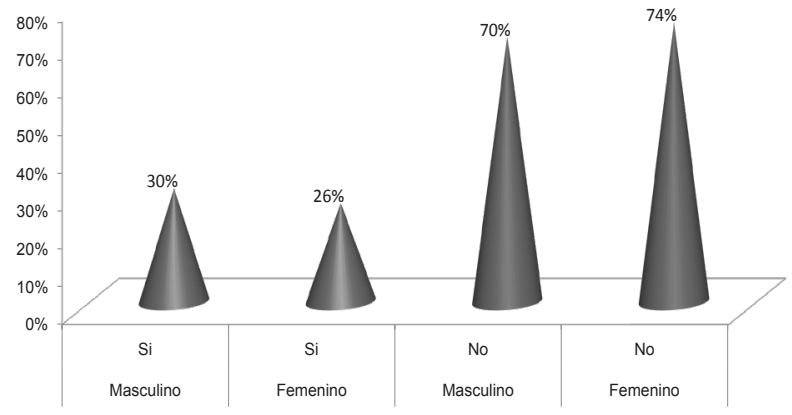

En menor frecuencia las trabajadoras del sexo refirieron la presencia del virus de Papiloma Humano con un $5 \%$.(ver figura 7 )

La tabla 4 nos indica que el uso de drogas endovenosas en los participantes fue relativamente bajo, únicamente las mujeres refirieron haber tenido contacto con dichas drogas en un $4 \%$, no siendo así para los conductores que aseguraron nunca haber tenido contacto con este tipo de sustancias.

La exposición de los participantes a recepciones sanguíneas fue poco relevante ya que un bajo porcentaje de estos estuvo expuesto a la infección, $12 \%$ de los conductores y un $28 \%$ de las trabajadoras sexuales. Sabemos que se han hecho estudios que revelan que este comportamiento de riesgo ha ido disminuyendo con la utilización de mejores técnicas de laboratorio y
Figura 7. Infecciones de T. sexual mas frecuentes en los participantes

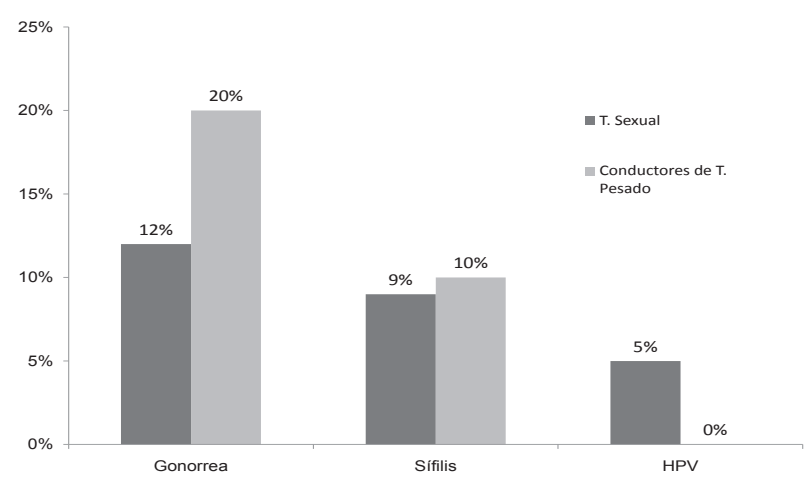

Tabla 4. Otros factores asociados a la infección por VIH

\begin{tabular}{ccccccc}
\hline \multirow{2}{*}{ Variables } & \multicolumn{2}{c}{$\begin{array}{l}\text { Uso de droga } \\
\text { endovenosa }\end{array}$} & \multicolumn{2}{c}{$\begin{array}{c}\text { Recepciones } \\
\text { sanguíneas }\end{array}$} & \multicolumn{2}{c}{$\begin{array}{c}\text { Tatuajes } \\
\text { corporales }\end{array}$} \\
\cline { 2 - 7 } & $\mathrm{Si}$ & $\mathrm{No}$ & $\mathrm{Si}$ & $\mathrm{No}$ & $\mathrm{Si}$ & No \\
\hline $\begin{array}{c}\text { Trabajadoras } \\
\text { sexuales }\end{array}$ & $4 \%$ & $96 \%$ & $28 \%$ & $72 \%$ & $26 \%$ & $74 \%$ \\
Conductores & - & $100 \%$ & $12 \%$ & $88 \%$ & $38 \%$ & $62 \%$ \\
\hline
\end{tabular}

un buen control de calidad en los hospitales y bancos de sangre, aunque nunca va dejar de ser un riesgo importante para contraer el virus.

También el uso de tatuajes aunque no predominó en este estudio, se encontró en un $38 \%$ para los transportistas y un $26 \%$ para las trabajadoras del sexo.(ver tabla 4 )

\section{Seroprevalencia de VIH en estos dos grupos de riesgo}

Después de realizarles las pruebas necesarias para detección de anticuerpos anti-VIH a los participantes, se encontró un caso seropositivo al virus de inmunodeficiencia humana en el grupo de los conductores de transporte pesado, correspondiendo esto al $1 \%$ de toda la población en estudio. (ver figura 8).

En las trabajadoras sexuales no se encontró ningún caso de $\mathrm{VIH}$, este hallazgo es similar al reportado por el Ministerio de Salud de Nicaragua, que indica una baja prevalencia de infección en este grupo; es por esto que es sumamente necesario e importante que así como se monitorea la situación del VIH en las trabajadoras sexuales, se debe también promover una búsqueda activa de casos en el grupo de conductores de transporte pesado, que por sus comportamientos de riesgo pueden estar contribuyendo a la diseminación de esta infección. 
Figura 8. Seroprevalencia de VIH en trabajadoras sexuales y conductores de transporte pesado en León. Mayo -agosto 2007

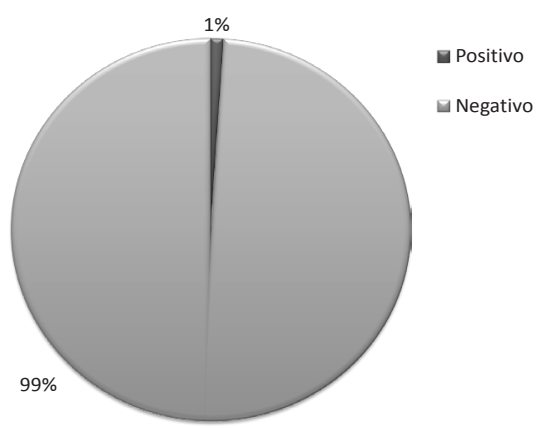

Este dato indica que de cada 50 conductores de transporte pesado hay uno con $\mathrm{VIH} / \mathrm{Sida}$, alarmante no sólo para nuestro país sino también para los países vecinos ya que por pertenecer a este grupo sabemos que van de un lugar a otro pudiendo no tener la debida precaución y de esta forma infectar a otros con los que ellos estén en estrecho contacto.

Consideramos que en este estudio no se encontró ningún caso $\mathrm{VIH}$ positivo en las mujeres ya que la razón de masculinidad respecto a estas en Nicaragua es de 2:1, por lo tanto si para cada 50 conductores que circulan por el by pass hay uno infectado, por cada 100 trabajadoras sexuales podría haber una infectada y se tendría que aumentar la muestra en esta misma población para poder encontrar casos positivos en estas.

No se debe descartar la posibilidad que algún participante podría estar pasando por un periodo de ventana en el momento de haberle realizado el estudio ya que este se realizó en un corto periodo de tiempo.

\section{CONCLUSIONES Y RECOMENDACIONES}

El uso del preservativo es un factor clave para la prevención del VIH/SIDA. Por tanto, se debe destacar que las trabajadoras del sexo son las que presentan un mayor porcentaje en siempre hacer uso de este en todas sus relaciones sexuales y los conductores de transporte pesado tienen un porcentaje más bajo no obstante los factores que tuvieron mayor impacto en cuanto a la transmisión fueron los siguientes:

Consideramos que la escolaridad que alcanzaron los participantes de esta investigación es un punto clave ya sea para la prevención o la diseminación de la enfermedad, teniendo ésta última mayor relevancia para el caso de las trabajadoras sexuales ya que en su mayoría llegaron tan solo a primaria y teniendo en cuenta que una buena parte son analfabetas consideramos que desconocen acerca de prácticas seguras para la prevención de esta pandemia.

El hecho de haber tenido contactos sexuales fuera de la ciudad y con personas desconocidas es un factor muy importante que contribuye a la propagación de la infección. Se observó una asociación importante entre el número de compañeros sexuales y la prevalencia de ITS.

Se encontró un único caso VIH-positivo en las pruebas realizadas Capillus y Uni-gold a 50 trabajadoras del sexo y 50 conductores de transporte pesado que circulan por el área del by pass de la ciudad de León en el período de Mayo- Agosto del 2007, al cual se le brindó atención psicológica y la oportunidad para integrarse al Programa de Enfermedades Infecciosas/ VIH-Sida del Hospital Escuela Oscar Danilo Rosales.

En este trabajo se le recomienda al MINSA-León, continuar brindando educación sexual a las trabajadoras del sexo e iniciar un plan de educación dirigidos a los conductores de transporte pesado que circulan por el by pass de la ciudad de León, implementar sistemas de vigilancia activa en estos dos grupos de riesgo que permitan monitorear la aparición de nuevos casos.

\section{REFERENCIAS BIBLIOGRÁFICAS}

1. PRIETO J. "Sida, crónica y protagonistas." Revista El origen del $\mathrm{VIH}$. Accesado el 17/marzo/2007 en www.sidalava.org/WEB castellano/2_vih_historia. $\mathrm{htm}$

2. RODRÍGUEZ VIGNART G. VIH positivo. Com. Historia del VIH/SIDA. Accesado el 18/marzo/2007 en www.unaids.org/bangkok2004/GAR2004html

3. Biblioteca de consulta Microsoft $\AA$ encarta $₫ 2005$ (C1993-2004. síndrome de inmunodeficiencia adquirida (SIDA). Modo de transmisión. Accesado el 16/marzo/2007

4. QUEZADA W., CHAVARRÍA R. (2001) Seroprevalencia de VIH/SIDA en población de 15-49 años de Corinto. Tesis Monográfica, UNANLEÓN.

5. ROMERO L., DELGADO B., Programa Nacional de ITS/VIH/SIDA, con aportes del equipo nacional de Vigilancia Epidemiológica. Estudio de prevalencia de VIH en mujeres embarazadas atendidas en unidades de salud durante el período de Noviembre 2004-Febrero 2005. semana 32, año 2005. 
Accesado el 18/marzo/2007 en www.minsa.gob.ni/ vigepi/html/boletin/2005/editorial32.html

6. Informe sobre la epidemia mundial de SIDA, julio 2004. Accesado el 17/marzo/2007 en www.unaids. org/bangkok2004/GAR2004html

7. FLORES M. MINSA atendió 38 casos de $\mathrm{VIH} /$ SIDA en León. El nuevo diario todo el poder de la información, Managua-Nicaragua domingo 18 de diciembre 2005 edición 9105. Accesado el 18/marzo/2007 en www.wlnuwvodiario.com. ni/2005/12/18/nacionales.

8. Antecedentes de la epidemia en Nicaragua. Accesado el 18/marzo/2007 en www.pasca.org/ nograficas/situación/antecedentes_nicaragua.pdf

9. Ministerio de Salud de Nicaragua. Boletín Epidemiológico. "Situación epidemiológico del $\mathrm{VIH} /$ SIDA en Nicaragua hasta el primer semestre del 2007"

10. Wikipedia. La Enciclopedia Libre VIH. 2007-06-21. Cód de versión de pág \#9611659 http://es.wikipedia. org/w/index.php?title=VIH\&oldid=9611659

11. QUEVEDO B. G. (2006) Informe final del estudio nacional sobre violencia contra las mujeres y $\mathrm{VIH}$. O.P.S. Managua, Noviembre.

12. OMS. Estimaciones de la OMS. VIH/SIDA. Revisión febrero 1997-1998. accesado el 17/marzo/2007 en www.ctv.es/USERS/fpardo/vihoms01.html

13. MEDRANO L. M., MEDRANO G. C., Enfermedades de Transmisión sexual en trabajadoras del sexo del municipio de Chinandega en el período de Abril a Junio del año 2000. Tésis Monográfica. UNANLeón

14. Family Health International (FHI). Hombres que tienen relaciones con hombres. 2007. WWW. FHI,ORG/SP/TOPICS/INDEX.HTM 